УДК 796.417.2

\title{
СОВЕРШЕНСТВОВАНИЕ ТЕХНИЧЕСКОЙ ПОДГОТОВЛЕННОСТИ ВЫСОКОКВАЛИФИЦИРОВАННЫХ АКРОБАТОВ, СПЕЦИАЛИЗИРУЮЩИХСЯ В МУЖСКИХ ГРУППАХ, ПОСРЕДСТВОМ СОСТАВЛЕНИЯ И ПРИМЕНЕНИЯ МОДЕЛЬНЫХ ХАРАКТЕРИСТИК
}

\section{Тронев Вячеслав Вячеславович} Пилюк Николай Николаевич д.П.н., профессор Жигайлова Лариса Валентиновна к.П.н., доцент

\section{Тихонова Ирина Владимировна} к.П.н., доцент ФГБОУ ВО «Кубанский государственный университет физической культуры, спорта и туризма»

Аннотация: Спортивная акробатика зрелищный вид спорта, связанный с выполнением сложно-координационных двигательных действий, как в одиночку, так и в паре или группе со своими партнерами. Особенно четко это можно отметить в виде спортивной акробатики - мужские группы (группа состоит из четырех юношей/мужчин). Данный вид спорта требует от спортсменов трудолюбия, исполнительности и мужества для достижения значительных спортивных результатов.

Так как спортивная акробатика является сложно-координационным видом спорта, требующим большой подготовленности как физической, так и технической. Зачастую акробатические упражнения или отдельно взятые элементы представляют собой сложные по координации движения различными частями тела, выполняемые чаше всего в условиях опоры руками, а не ногами. Так же множество элементов выполняется на большой высоте и в безопорном положении. Такие условия требуют от спортсмена точного сопоставления скорости суставных движений, относительно скорости вращения всего тела в пространстве, и точного соотношения мышечных усилий с силами инерции.

Ключевые слова: спортивная подготовка, спортивная акробатика, мужские группы, техническая подготовка. 


\title{
IMPROVING THE TECHNICAL TRAINING OF ELITE ACROBATS MEN'S GROUP BY DRAWING UP AND APPLYING MODEL CHARACTERISTICS
}

\section{Tronev Vyacheslav Vyacheslavovich Pilyuk Nikolay Nikolaevich Jigalova Larisa Valentinovna Tikhonova Irina Vladimirovna}

\begin{abstract}
Sports acrobatics is a spectacular sport associated with performing complex coordination motor actions, both alone and in a couple or group with their partners. This can be especially clearly noted in the form of sports acrobatics - men's groups (the group consists of four boys/men). This type of sport requires hard work, diligence and courage from athletes to achieve significant sporting results.

Since sports acrobatics is a complex coordination sport that requires a lot of preparation, both physical and technical. Often acrobatic exercises or individual elements are difficult to coordinate the movement of different parts of the body, performed most often in conditions of support with the hands, not with the feet. Also, many elements are performed at a high height and in a non-supporting position. Such conditions require the athlete to accurately compare the speed of joint movements, relative to the speed of rotation of the entire body in space, and the exact ratio of muscle effort to inertia forces.
\end{abstract}

Key words: sports training, sports acrobatics, men's groups, technical training.

\section{1 Показатели модельных характеристик технической подготовленности акробатов высокой квалификации, специализирующихся в мужских группах}

Для качественного контроля технической подготовленности высококвалифицированных акробатов, специализирующихся в мужских группах, показатели модельных характеристик играют важную роль. Набор тестов, достоверно отображающих уровень технической подготовленности высококвалифицированных акробатов, должны быть использованы как основа программ совершенствования технической подготовленности.

Информативные тесты, отражающие уровень технической подготовленности высококвалифицированных акробатов отбирались на основе расчётов коэффициентов корреляции между результатами тестирования по подобранным тестам и критериями информативности, в качестве которых 
использовалась общая сумма балов, полученных спортсменами за выполнение трех упражнений многоборья на соревнованиях.

В ходе проведения исследования было проведено тестирование мужских групп высокой квалификации специально составленными комплексами упражнений для каждого партнера в группе (верхний, второй средний, первый средний, нижний) [1 c. 28]. Составленные тесты отражали две стороны технической подготовленности спортсменов - статическую (баланс) и динамическую (вольтиж), и представляющих основные упражнения необходимые для выполнения в последующем более сложных технических элементов [2 с. 48, 3 с. 245]. Результаты тестирования, корреляционного анализа, характеризующего информативность тестов технической подготовленности, приведены в табл. 1-4.

Таблица 1

Информативность показателей технической подготовленности акробатов верхних высокой квалификации, специализирующихся

в мужских группах $(\mathbf{n}=10)$

\begin{tabular}{|l|l|l|l|l|}
\hline Показатели & $\mathrm{M}$ & $\delta$ & $\mathrm{r}$ & $\mathrm{P}$ \\
\hline $\begin{array}{l}\text { Выполнение сальто назад в группировке с места на } \\
\text { ограниченной площадке (количество раз) }\end{array}$ & 10,8 & 2,8 & 0,56 & $\mathrm{P}<0,05$ \\
\hline Удержание стойки на одной руке на стоялках (с) & 227,3 & 47,9 & 0,61 & $\mathrm{P}<0,05$ \\
\hline Удержание упора углом на одной руке на полу (с) & 150 & 47,4 & 0,60 & $\mathrm{P}<0,05$ \\
\hline $\begin{array}{l}\text { Стойка силой из упора углом на стоялках (количество } \\
\text { раз) }\end{array}$ & 26,5 & 4,9 & 0,58 & $\mathrm{P}<0,05$ \\
\hline $\begin{array}{l}\text { Стойка на одной руке силой из упора углом на голове } \\
\text { партнера (количество раз) }\end{array}$ & 2,5 & 0,8 & 0,51 & $\mathrm{P}>0,05$ \\
\hline
\end{tabular}

Таблица 2

Информативность показателей технической подготовленности акробатов вторых средних высокой квалификации, специализирующихся

в мужских группах $(\mathrm{n}=10)$

\begin{tabular}{|l|c|c|c|c|}
\hline Показатели & $\mathrm{M}$ & $\delta$ & $\mathrm{r}$ & $\mathrm{P}$ \\
\hline $\begin{array}{l}\text { Бросок верхнего двумя руками с последующей ловлей } \\
\text { (темп из рук в руки) (количество раз) }\end{array}$ & 15 & 2,8 & 0,55 & $\mathrm{P}<0,05$ \\
\hline Удержание упора углом на стоялках (с) & 212,8 & 30,2 & 0,61 & $\mathrm{P}<0,05$ \\
\hline $\begin{array}{l}\text { Приседания с верхним удерживаемым в прямых руках } \\
\text { (количество раз) }\end{array}$ & 11,7 & 2,6 & 0,59 & $\mathrm{P}<0,05$ \\
\hline $\begin{array}{l}\text { Удержание верхнего в прямых руках на ограниченной } \\
\text { опоре (с) }\end{array}$ & 118,3 & 19,1 & 0,57 & $\mathrm{P}<0,05$ \\
\hline Удержание верхнего на голове (с) & 143,5 & 47,3 & 0,56 & $\mathrm{P}<0,05$ \\
\hline
\end{tabular}


Таблица 3

Информативность показателей технической подготовленности акробатов первых средних высокой квалификации, специализирующихся

в мужских группах $(\mathrm{n}=10)$

\begin{tabular}{|l|c|c|c|c|}
\hline Показатели & $\mathrm{M}$ & $\delta$ & $\mathrm{r}$ & $\mathrm{P}$ \\
\hline $\begin{array}{l}\text { Бросок «темп» верхнего скрестным хватом кистей с } \\
\text { нижним с последующей ловлей (количество раз) }\end{array}$ & 18,8 & 3,5 & 0,59 & $\mathrm{P}<0,05$ \\
\hline $\begin{array}{l}\text { Удержание партнеров в «драйке» на ограниченной } \\
\text { опоре (с) }\end{array}$ & 182,3 & 38,3 & 0,61 & $\mathrm{P}<0,05$ \\
\hline Приседания в «драйке» (количество раз) & 13,3 & 3,8 & 0,58 & $\mathrm{P}<0,05$ \\
\hline $\begin{array}{l}\text { Приседания с верхним удерживаемым в прямых руках } \\
\text { (количество раз) }\end{array}$ & 25,5 & 5,1 & 0,57 & $\mathrm{P}<0,05$ \\
\hline Удержание партнера в прямых руках (с) & 144,7 & 44,1 & 0,56 & $\mathrm{P}<0,05$ \\
\hline
\end{tabular}

Таблица 4

Информативность показателей технической подготовленности акробатов - нижних высокой квалификации, специализирующихся в мужских группах $(\mathrm{n}=10)$

\begin{tabular}{|l|l|l|l|l|}
\hline Показатели & $\mathrm{M}$ & $\delta$ & $\mathrm{r}$ & $\mathrm{P}$ \\
\hline $\begin{array}{l}\text { Бросок верхнего скрестным хватом кистей с первым } \\
\text { средним (решетка) (количество раз) }\end{array}$ & 18,8 & 3,5 & 0,55 & $\mathrm{P}<0,05$ \\
\hline Удержание партнеров в «драйке» (с) & 239,7 & 42,3 & 0,59 & $\mathrm{P}<0,05$ \\
\hline Приседания в «драйке» (количество раз) & 18 & 2,9 & 0,57 & $\mathrm{P}<0,05$ \\
\hline $\begin{array}{l}\text { Комплекс перестроений из трех статических баз } \\
\text { (количество раз) }\end{array}$ & 24,2 & 5,4 & 0,51 & $\mathrm{P}>0,05$ \\
\hline Ходьба в «драйке» (с) & 101,2 & 32,2 & 0,58 & $\mathrm{P}<0,05$ \\
\hline
\end{tabular}

Анализ полученных результатов тестирования и расчет коэффициента корреляции с оценками за соревновательные упражнения, полученные на Всероссийских соревнованиях, позволяет сделать следующие выводы сделать следующие заключения.

Для верхних, достоверно зависимыми являются все критерии оценки технической подготовленности кроме упражнения «Стойка на одной руке силой из упора углом на голове партнера», но данное упражнение требует дальнейшего изучения и проверки, так как является базовым и самым используемым техническим элементом в парно-групповой акробатике.

Все критерии, подобранные для первых средних и вторых средний также являются достоверно зависимыми по отношению к соревновательному 
результату и подлежат дальнейшей разработке в модельных характеристика технической подготовленности.

Для нижних, достоверно зависимыми являются все критерии оценки технической подготовленности кроме упражнения «Комплекс перестроений из трех статических баз», но, как и в случае с верхними, правильное перестроение во множественные базовые построения пирамид является неотъемлемой частью набора трудности упражнений в мужских группах.

\section{2 Уровни развития и модельные характеристики технической подготовленности высококвалифицированных акробатов, специализирующихся в мужских группах}

Ввиду того, что для эффективной практической работы и оптимальным управлением тренировочных мероприятий, тренеру необходимы требования к количественным характеристикам технической подготовленности акробатов высокой квалификации специализирующихся в мужских группах необходимо иметь оценочную шкалу для определения показателей технической подготовленности [4 с. 147].

В связи с этим разработка уровней развития и модельных характеристик, а так же ориентация на конкретные величины этих характеристик при подготовке спортсменов высокой квалификации приобретает важное значение [5 с. 231, 6 с. 36]. Уровни развития показателей технической подготовленности определялись на основе метода, с использованием средних значений и величин стандартных отклонений. Нами были рассчитаны значения 5 уровней (высокого, выше среднего, среднего, ниже среднего, низкого) показателей технической подготовленности акробатов специализирующихся в мужских группах (табл. 5-8).

Таблица 5

Уровни развития показателей технической подготовленности верхних

\begin{tabular}{|l|l|l|l|l|l|}
\hline \multicolumn{5}{|c|}{ Уровни развития } \\
\hline Показатели & Низкий & $\begin{array}{l}\text { Ниже } \\
\text { среднего }\end{array}$ & Средний & $\begin{array}{l}\text { Выше } \\
\text { среднего }\end{array}$ & Высокий \\
\hline $\begin{array}{l}\text { Выполнение } \\
\text { группированного сальто } \\
\text { назад с места на } \\
\begin{array}{l}\text { ограниченном } \\
\text { пространстве (количество } \\
\text { раз) }\end{array}\end{array}$ & 7,9 и менее & $8-9,3$ & $9,4-12,2$ & $12,3-13,6$ & 13,7 и более \\
\hline
\end{tabular}




\begin{tabular}{|l|l|l|l|l|l|}
\hline $\begin{array}{l}\text { Удержание стойки на } \\
\text { одной руке на стоялках (с) }\end{array}$ & $\begin{array}{l}179,3 \text { и } \\
\text { менее }\end{array}$ & $179,4-203,34$ & $\begin{array}{l}203,35- \\
251,25\end{array}$ & $251,26-275,2$ & $\begin{array}{l}275,3 \text { и } \\
\text { более }\end{array}$ \\
\hline $\begin{array}{l}\text { Удержание упора углом на } \\
\text { одной руке на полу (с) }\end{array}$ & $\begin{array}{l}102,5 \text { и } \\
\text { менее }\end{array}$ & $102,6-126,4$ & $126,3-173,7$ & $173,8-197,4$ & $\begin{array}{l}197,5 \text { и } \\
\text { более }\end{array}$ \\
\hline $\begin{array}{l}\text { Стойка силой из упора } \\
\text { углом на стоялках } \\
\text { (количество раз) }\end{array}$ & 21,5 и менее & $21,6-24,04$ & $24,05-28,95$ & $28,96-31,4$ & 31,5 и более \\
\hline $\begin{array}{l}\text { Стойка на одной руке } \\
\text { силой из упора углом на } \\
\text { голове партнера } \\
\text { (количество раз) }\end{array}$ & 1,6 и менее & $1,7-2,0$ & $2,1-2,9$ & $3,0-3,3$ & 3,4 и более \\
\hline
\end{tabular}

Таблица 6

Уровни развития показателей технической подготовленности

вторых средних

\begin{tabular}{|c|c|c|c|c|c|}
\hline \multicolumn{6}{|c|}{ Уровни развития } \\
\hline Показатели & Низкий & $\begin{array}{l}\text { Ниже } \\
\text { среднего }\end{array}$ & Средний & $\begin{array}{l}\text { Выше } \\
\text { среднего }\end{array}$ & Высокий \\
\hline $\begin{array}{l}\text { Бросок верхнего двумя } \\
\text { руками с последующей } \\
\text { ловлей (темп из рук в } \\
\text { руки) (количество раз) }\end{array}$ & 12,1 и менее & $12,2-13,5$ & $13,6-16,4$ & $16,5-17,8$ & 17,9 и более \\
\hline $\begin{array}{l}\text { Удержание упора углом на } \\
\text { стоялках (c) }\end{array}$ & $\begin{array}{l}182,5 \text { и } \\
\text { менее }\end{array}$ & $182,6-197,6$ & $197,7-227,9$ & $228-243$ & $\begin{array}{l}243,1 \text { и } \\
\text { более }\end{array}$ \\
\hline $\begin{array}{l}\text { Приседания с верхним } \\
\text { удерживаемым в прямых } \\
\text { руках (количество раз) }\end{array}$ & 9 и менее & $9,1-10,4$ & $10,4-13$ & $13,1-14,3$ & 14,4 и более \\
\hline $\begin{array}{l}\text { Удержание верхнего в } \\
\text { прямых руках на } \\
\text { ограниченной опоре (c) }\end{array}$ & 99,1 и менее & $99,2-108,74$ & $\begin{array}{l}108,75- \\
127,85\end{array}$ & $127,86-137,4$ & $\begin{array}{l}137,5 \text { и } \\
\text { более }\end{array}$ \\
\hline $\begin{array}{l}\text { Удержание верхнего на } \\
\text { голове (c) }\end{array}$ & 96,1 и менее & $96,2-119,84$ & $\begin{array}{l}119,85- \\
167,15\end{array}$ & $167,16-190,8$ & $\begin{array}{l}190,9 \text { и } \\
\text { более }\end{array}$ \\
\hline
\end{tabular}

Таблица 7

\section{Уровни развития показателей технической подготовленности}

\section{первых средних}

\begin{tabular}{|l|l|l|l|l|l|}
\hline \multicolumn{5}{|c|}{ Уровни развития } \\
\hline Показатели & Низкий & $\begin{array}{l}\text { Ниже } \\
\text { среднего }\end{array}$ & Средний & $\begin{array}{l}\text { Выше } \\
\text { среднего }\end{array}$ & Высокий \\
\hline $\begin{array}{l}\text { Бросок верхнего } \\
\text { скрестным хватом кистей с } \\
\begin{array}{l}\text { нижним (решетка) } \\
\text { (количество раз) }\end{array}\end{array}$ & 15,5 и менее & $15,6-16,2$ & $16,3-17,7$ & $17,8-18,4$ & 18,5 и более \\
\hline
\end{tabular}




\begin{tabular}{|l|l|l|l|l|l|}
\hline $\begin{array}{l}\text { Удержание партнеров в } \\
\text { «драйке» на ограниченной } \\
\text { опоре (с) }\end{array}$ & 143 и менее & $144-173,14$ & $\begin{array}{l}173,15- \\
201,45\end{array}$ & $201,46-220,6$ & $\begin{array}{l}220,7 \text { и } \\
\text { более }\end{array}$ \\
\hline $\begin{array}{l}\text { Приседания в «драйке» } \\
\text { (количество раз) }\end{array}$ & 9,4 и менее & $9,5-11,3$ & $11,4-15,2$ & $15,3-17,1$ & 17,2 и более \\
\hline $\begin{array}{l}\text { Приседания с верхним } \\
\text { удерживаемым в прямых } \\
\text { руках (количество раз) }\end{array}$ & 20,3 и менее & $20,4-22,94$ & $22,95-28,05$ & $28,06-30,6$ & 30,7 и более \\
\hline $\begin{array}{l}\text { Удержание партнера в } \\
\text { прямых руках (с) }\end{array}$ & $\begin{array}{l}100,5 \text { и } \\
\text { менее }\end{array}$ & $100,6-122,64$ & $\begin{array}{l}122,65- \\
166,75\end{array}$ & $166,76-188,8$ & $\begin{array}{l}188,9 \text { и } \\
\text { более }\end{array}$ \\
\hline
\end{tabular}

Таблица 8

\section{Уровни развития показателей технической подготовленности нижних}

\begin{tabular}{|l|l|l|l|l|l|}
\hline \multicolumn{5}{|c|}{ Уровни развития } \\
\hline Показатели & Низкий & $\begin{array}{l}\text { Ниже } \\
\text { среднего }\end{array}$ & Средний & $\begin{array}{l}\text { Выше } \\
\text { среднего }\end{array}$ & Высокий \\
\hline $\begin{array}{l}\text { Бросок верхнего } \\
\text { скрестным хватом кистей с } \\
\text { первым средним } \\
\text { («решетка») (количество } \\
\text { раз) }\end{array}$ & 15,2 и менее & $15,3-17,04$ & $17,05-20,55$ & $20,56-22,3$ & 22,4 и более \\
\hline $\begin{array}{l}\text { Удержание партнеров в } \\
\text { «драйке» (с) }\end{array}$ & $\begin{array}{l}197,3 \text { и } \\
\text { менее }\end{array}$ & $197,4-218,54$ & $\begin{array}{l}218,55- \\
260,85\end{array}$ & $260,86-282$ & $\begin{array}{l}282,1 \text { и } \\
\text { более }\end{array}$ \\
\hline $\begin{array}{l}\text { Приседания в «драйке» } \\
\text { (количество раз) }\end{array}$ & 15 и менее & $15,1-16,54$ & $16,55-19,45$ & $19,46-20,9$ & 21 и более \\
\hline $\begin{array}{l}\text { Комплекс перестроений из } \\
\text { трех статических баз } \\
\text { (количество раз) }\end{array}$ & 18,7 и менее & $18,8-21,4$ & $21,5-26,9$ & $27-29,6$ & 29,7 и более \\
\hline \begin{tabular}{l} 
Ходьба в «драйке» (с) \\
\hline
\end{tabular} & 68,9 и менее & $69-85$ & $85,1-117,3$ & $117,4-133,4$ & $\begin{array}{l}133,5 \text { и } \\
\text { более }\end{array}$ \\
\hline
\end{tabular}

Кроме этого нами были разработаны модельные значения изучаемых показателей, характеризующие техническую подготовленность мужских групп.

В основу выявления конкретных величин модельных значений положен анализ этих показателей, характеризующий техническую подготовленность двух акробатов: нижних, первых средних, вторых средних и верхних, достигших наивысших спортивно-технических результатов в исследуемой группе за 2017-2019 г. Модельные характеристики приведены в табл. 9. 
Таблица 9

\section{Модельные характеристики акробатов высокой квалификации специализирующихся в мужских группах}

\begin{tabular}{|c|c|c|}
\hline Тесты & Значения & $\begin{array}{l}\text { Уровень } \\
\text { развития }\end{array}$ \\
\hline \multicolumn{3}{|l|}{ Верхние } \\
\hline $\begin{array}{l}\text { Выполнение группированного сальто назад с места на ограниченной } \\
\text { площадке (количество раз) }\end{array}$ & 14,0 & Высокий \\
\hline Удержание стойки на одной руке на стоялках (c) & 285,5 & Высокий \\
\hline Удержание упора углом на одной руке на полу (c) & 203,0 & Высокий \\
\hline Стойка силой из упора углом на стоялках (количество раз) & 31,5 & Высокий \\
\hline $\begin{array}{l}\text { Стойка на одной руке силой из упора углом на голове партнера } \\
\text { (количество раз) }\end{array}$ & 4,0 & Высокий \\
\hline \multicolumn{3}{|l|}{ Вторые средние } \\
\hline $\begin{array}{l}\text { Бросок верхнего двумя руками с последующей ловлей(темп из рук в } \\
\text { руки)(количество раз) }\end{array}$ & 17,0 & $\begin{array}{l}\text { Выше } \\
\text { среднего }\end{array}$ \\
\hline Удержание упора углом на стоялках (c) & 232,5 & $\begin{array}{l}\text { Выше } \\
\text { среднего }\end{array}$ \\
\hline Приседания с верхним удерживаемым в прямых руках (количество раз) & 14,5 & Высокий \\
\hline Удержание верхнего в прямых руках на ограниченной опоре (c) & 136,5 & $\begin{array}{l}\text { Выше } \\
\text { среднего }\end{array}$ \\
\hline Удержание верхнего на голове (c) & 176,0 & $\begin{array}{l}\text { Выше } \\
\text { среднего }\end{array}$ \\
\hline \multicolumn{3}{|l|}{ Первые средние } \\
\hline $\begin{array}{l}\text { Бросок верхнего скрестным хватом кистей с нижним(решетка) } \\
\text { (количество раз) }\end{array}$ & 22,5 & Высокий \\
\hline Удержание партнеров в «драйке» на ограниченной опоре (c) & 214,5 & $\begin{array}{l}\text { Выше } \\
\text { среднего }\end{array}$ \\
\hline Приседания в «драйке» (количество раз) & 16,5 & $\begin{array}{l}\text { Выше } \\
\text { среднего }\end{array}$ \\
\hline Приседания с верхним удерживаемым в прямых руках (количество раз) & 30,0 & $\begin{array}{l}\text { Выше } \\
\text { среднего }\end{array}$ \\
\hline Удержание партнера в прямых руках (c) & 172,0 & $\begin{array}{l}\text { Выше } \\
\text { среднего }\end{array}$ \\
\hline \multicolumn{3}{|l|}{ Нижние } \\
\hline $\begin{array}{l}\text { Бросок верхнего скрестным хватом кистей с первым средним (решетка) } \\
\text { (количество раз) }\end{array}$ & 22,5 & Высокий \\
\hline Удержание партнеров в «драйке» (c) & 291,0 & Высокий \\
\hline Приседания в «драйке» (количество раз) & 21,0 & Высокий \\
\hline Комплекс перестроений из трех статических баз (количество раз) & 30,5 & Высокий \\
\hline Ходьба в «драйке»(с) & 137,5 & Высокий \\
\hline
\end{tabular}


Как показывает анализ результатов тестирования, сильнейших акробатов в данной группе характеризуют следующие показатели - «высокие» и «выше среднего» [7 с. 102].

Предложенные модельные характеристики технической подготовленности акробатов высокой квалификации нельзя рассматривать как полную, законченную модель. Однако, уже сейчас используя модельные характеристики технической подготовленности акробатов высокой квалификации специализирующихся в мужских группах, можно оценить их потенциал, выявить сильные и слабые стороны подготовленности спортсменов и наметить пути дальнейшего совершенствования их спортивного мастерства [8 c. 99].

\section{3 Совершенствование технической подготовленности высококвалифицированных акробатов, специализирующихся в мужских группах}

Модельные характеристики технической подготовленности высококвалифицированных акробатов являются средством контроля, но спортивная подготовка не ограничивается контролем. После определения мест, в которых спортсмен показывает результаты хуже, чем от него требуется, следует применять средства совершенствования технической подготовленности.

Одним из средств совершенствования технической подготовленности, необходимым в процессе подготовки высококвалифицированных акробатов высокой квалификации, специализирующихся в мужских группах, мы считаем программу совершенствования технической подготовленности.

Основой программы совершенствования технической подготовленности должны являться тесты - упражнения, при помощи которых производится тестирование уровня технической подготовленности. Также дополнительно к техническим упражнениям мы решили добавить несколько производных технических упражнений, а также средства специальной физической подготовки.

Исходя из выше сказанного, мы можем представить комплексы упражнений для совершенствования технической подготовленности высококвалифицированных акробатов, специализирующихся в мужских группах.

Упражнения для верхних и дозировка представлены в табл. 10.

1-в. Выполнение сальто назад в группировке на ограниченной опоре. На гимнастическом ковре с очерченным квадратом в $20 \mathrm{~cm}^{2}$, задача - максимально большое количество раз подряд выполнить группированное сальто назад не 
выходя за очерченную площадь, соблюдая правильную технику выполнения элемента.

2-в. Удержание стойки на одной руке на стоялках. На специально сделанном тренажере «стоялка», имитирующем голову/руку партнера-нижнего, задача - удерживать положение стойки на одной руке, без сильных изменений положения для удержания баланса.

3-в. Удержание упора углом на одной руке на полу. На широкой, ровной и жесткой площадке (простой пол), необходимо удерживать положение угол на одной руке в течение максимально большого времени сохраняя технически правильное положение элемента.

4-в. Стойка силой из упора углом на стоялках («спичак»). На тренажере «стоялках» в количестве двух штук, выполняется движение выхода в стойку на двух руках из положения углом.

5-в. Стойка силой на одной руке из упора углом на голове партнера (жим на одной в стойку). Каждый испытуемый должен был выполнить максимальное количество «жимов» на голове у своего непосредственного партнера (второго среднего), соблюдая правильную технику исполнения.

6-в. Удержание стойки на одной руке на полу. Задача - удерживать положение стойки на одной руке, без сильных изменений положения для удержания баланса.

7-в. Стойка силой на одной руке из упора углом на стоялке (жим на одной в стойку) с незначительной опорой второй рукой. Необходимо выполнить максимальное количество «жимов» на стоялке возле гимнастической стенки, соблюдая правильную технику исполнения.

8-в. Выполнение сальто вперед в группировке на ограниченной опоре. На гимнастическом ковре с очерченным квадратом в $20 \mathrm{~cm}^{2}$, задача - максимально большое количество раз подряд выполнить группированное сальто вперед не выходя за очерченную площадь, соблюдая правильную технику выполнения элемента

9-в. Стойка силой из упора углом на полу («спичак»). Выполняется движение выхода в стойку на двух руках из положения углом / угол ноги врозь.

10-в. Поднимания ног на гимнастической стенке. Выполняется в висе на гимнастической стенке, ноги поднимаются вверх до касания в группировке. Задание может выполняться с отягощениями.

11-в. Сгибания и разгибания рук в стойке на руках. Выполняется на возвышении, так чтобы имелась возможность выполнять полностью сгибание 
рук с касанием опоры грудью. Выполняется с небольшой внешней поддержкой и без неё.

\section{Таблица 10}

\section{Дозировка упражнений для верхних}

\begin{tabular}{|c|c|c|c|}
\hline № упражнения & Дозировка & Количество подходов & Единицы измерения \\
\hline 1 -в & $10-15$ & $3-4$ & Количество раз \\
\hline $2-$ в & 300 & 4 & Секунды \\
\hline $3-$ в & 160 & 4 & Секунды \\
\hline $4-$ в & 30 & 4 & Количество раз \\
\hline $5-$ в & 5 & 5 & Количество раз \\
\hline 6-в & 300 & 4 & Секунды \\
\hline $7-$-в & 10 & 5 & Количество раз \\
\hline $8-$ в & $10-15$ & $3-4$ & Количество раз \\
\hline 9-в & 25 & 4 & Количество раз \\
\hline $10-в$ & 30 & 5 & Количество раз \\
\hline $11-в$ & 20 & 5 & Количество раз \\
\hline
\end{tabular}

Упражнения для вторых средних и дозировка представлены в табл. 11.

1-вс. Бросок верхнего двумя руками с последующей ловлей (темп из рук в руки). Задача - выполнить максимальное количество раз данного упражнения с максимальной амплитудой (вержний должен был каждый раз взлетать как можно выше от рук нижнего) и минимальным количеством переступаний ног во время ловли.

2-вс. Удержание упора углом на стоялках. Выполняется данное упражнение на специальном тренажере «стоялка», удерживая положение углом при соблюдении правильной техники исполнения: ноги должны быть параллельны полу, спина должна быть скруглена так что бы линия опоры руками проходила перпендикулярно ногам и находиться по середине бедра спортсмена.

3-вс. Приседания с верхним, удерживаемым в прямых руках. Удерживая своего партнера (верхнего), стоящего ногами в кистях прямых рук, необходимо выполнить максимальное количество раз приседание соблюдая технику исполнения: центр тяжести спортсмена не должен выходить за площадь опоры для сохранения равновесия, спина должна быть чуть-чуть прогнута, а руки должны быть строго вертикальны. 
4-вс. Удержание верхнего в прямых руках на ограниченной опоре. Необходимо удерживать своего партнера (верхнего) на ограниченной опоре с небольшим возвышением над полом.

5-вс. Удержание верхнего на голове. Верхний становиться двумя ногами на голову и старается как можно дольше простоять на голове, предоставляя партнеру самому выполнять балансировку верхнего.

6-вс. Стойка силой из упора углом на полу («спичак»). Выполняется движение выхода в стойку на двух руках из положения углом / угол ноги врозь.

7-вс. Сгибания и разгибания рук в стойке на руках. Выполняется на возвышении, так чтобы имелась возможность выполнять полностью сгибание рук с касанием опоры грудью. Выполняется с небольшой внешней поддержкой и без неё.

8-вс. Перестроение вниз и вверх на возвышение, с удержанием верхнего в прямых руках. Удерживая своего партнера (верхнего), стоящего ногами в кистях прямых рук, необходимо выполнить максимальное количество раз поднимание и спускание на возвышение, соблюдая технику исполнения: центр тяжести спортсмена не должен выходить за площадь опоры для сохранения равновесия, спина должна быть чуть-чуть прогнута, а руки должны быть строго вертикальны.

9-вс. Удержание упора углом на стоялках с верхним. Выполняется данное упражнение на специальном тренажере «стоялка», удерживая положение углом при соблюдении правильной техники исполнения: ноги должны быть параллельны полу, спина должна быть скруглена так что бы линия опоры руками проходила перпендикулярно ногам и находиться по середине бедра спортсмена.

10-вс. Выпрыгивания с верхним. Верхний располагается сидя на плечах второго среднего, и второй средний выполняет выпрыгивания из упора присев.

\section{Таблица 11}

\section{Дозировка упражнений для вторых средних}

\begin{tabular}{|c|c|c|c|}
\hline № упражнения & Дозировка & Количество подходов & Единицы измерения \\
\hline 1-вс & 20 & 4 & Количество раз \\
\hline $2-в с$ & 250 & 5 & Секунды \\
\hline 3-вс & 15 & 4 & Количество раз \\
\hline 4-вс & 150 & 4 & Секунды \\
\hline $5-в с$ & 170 & 4 & Секунды \\
\hline 6-вс & 25 & 4 & Количество раз \\
\hline
\end{tabular}




\begin{tabular}{|c|c|c|c|}
\hline $7-в с$ & 25 & 4 & Количество раз \\
\hline $8-в с$ & 25 & 4 & Количество раз \\
\hline $9-в с$ & 200 & 5 & Секунды \\
\hline $10-$ вс & 30 & 4 & Количество раз \\
\hline
\end{tabular}

Упражнения для первых средних и дозировка представлены в табл. 12.

1-пс. Бросок верхнего скрестным хватом кистей совместно с нижним с последующей ловлей «темп». Данное упражнение выполняется в паре с нижним. Испытуемые образуют скрестный хват кистями - «решётка», становятся в исходное положение для выполнения упражнения. Фиксируются расположение стоп. Задача - на количество выполнить «темпы» с максимальной амплитудой полета верхнего и минимальным количество переступаний ногами при ловле.

2-пс. Удержание партнеров в «драйке» на ограниченной опоре. Необходимо на время удержать базовое построение «драйку» без нарушений техники исполнения на ограниченной опоре с небольшим возвышением над полом. Для первого среднего партнерами становятся верхний и второй средний. Фиксируется само положение испытуемого (разворот плеч и локтей, высота подбородка, положение туловища).

3-пс. Приседания в «драйке». Необходимо в выше описанном положении «драйка» выполнить максимальное количество приседаний, удерживая равновесие как свое так и своих партнеров, при этом приседая максимально низко.

4-пс. Приседания с верхним удерживаемым в прямых руках. Удерживая своего партнера (верхнего), стоящего ногами в кистях прямых рук, спортсмен должен выполнить максимальное количество раз приседание соблюдая технику исполнения: центр тяжести спортсмена не должен выходить за площадь опоры для сохранения равновесия, спина должна быть чуть-чуть прогнута, а руки должны быть строго вертикальны.

5-пс. Удержание партнера в прямых руках. В данном упражнении партнером выступает второй средний. Необходимо удерживать партнера в прямых руках над головой соблюдая технику выполнения упражнения.

6-пс. Поднимание верхнего скрестным хватом кистей совместно с нижним. Данное упражнение выполняется в паре с нижним. Спортсмены образуют скрестный хват кистями - «решётка», становятся в исходное положение для выполнения упражнения. Фиксируются расположение стоп. 
Задача - на количество выполнить полную амплитуду движения как на «темп», выполняя полное приседание и поднимание верхнего на «решетке».

7-пс. Выпрыгивания с партнером. Партнер (второй средний) располагается сидя на плечах первого среднего, и выполняются выпрыгивания из упора присев.

8-пс. Приседания с партнером. Партнер (второй средний) располагается сидя на плечах первого среднего, и выполняются приседания с максимальной амплитудой.

9-пс. Перестроение вниз и вверх на возвышение, с удержанием верхнего в прямых руках. Удерживая своего партнера (верхнего), стоящего ногами в кистях прямых рук, необходимо выполнить максимальное количество раз поднимание и спускание на возвышение, соблюдая технику исполнения: центр тяжести спортсмена не должен выходить за площадь опоры для сохранения равновесия, спина должна быть чуть-чуть прогнута, а руки должны быть строго вертикальны.

10-пс. Ходьба в «драйке». В выше описанном базовом построении «драйка», первый средний ходит по гимнастическому ковру либо вперед-назад по одной линии, либо по кругу вдоль размеченных границ ковра. Упражнение выполняется на время.

\section{Таблица 12}

Дозировка упражнений для первых средних

\begin{tabular}{|c|c|c|c|}
\hline № упражнения & Дозировка & Количество подходов & Примечания \\
\hline 1-пс & 30 & 5 & Количество раз \\
\hline 2-пс & 220 & 4 & Секунды \\
\hline 3 -пс & 15 & 4 & Количество раз \\
\hline $4-п с$ & 30 & 4 & Количество ра3 \\
\hline 5 -пс & 200 & 4 & Количество ра3 \\
\hline 6-пс & 35 & 5 & Количество ра3 \\
\hline 7-пс & 30 & 4 & Количество раз \\
\hline 8 -пс & 45 & 4 & Количество раз \\
\hline 9-пс & 30 & 4 & Количество раз \\
\hline $10-п с$ & 100 & 5 & Секунды \\
\hline
\end{tabular}

Упражнения для нижних и дозировка представлены в табл. 13.

1-н. Бросок верхнего скрестным хватом кистей с первым средним. Данное упражнение выполняется в паре с первым средним. Испытуемые образуют скрестный хват кистями - «решётка», становятся в исходное положение для 
выполнения упражнения. Фиксируются расположение стоп испытуемых. Задача - на количество выполнить «темпы» с максимальной амплитудой полета верхнего и минимальным количество переступаний ногами при ловле.

2-н. Удержание партнеров в «драйке». Испытуемый должен на время удержать базовое построение «драйку» без нарушений техники исполнения на полу. Для нижнего партнерами становятся первый средний и второй средний. Фиксируется само положение испытуемого (разворот плеч и локтей, высота подбородка, положение туловища).

3-н. Приседания в «драйке». Испытуемый в выше описанном положении «драйка» должен выполнить максимальное количество приседаний, удерживая равновесие как свое так и своих партнеров, при этом приседая максимально низко.

4-н. Ходьба в «драйке». В выше описанном базовом построении «драйка», нижний ходит по гимнастическому ковру либо вперед-назад по одной линии, либо по кругу вдоль размеченных границ ковра. Упражнение выполняется на время.

5-н. Комплекс перестроений из трех статических баз. Испытуемый из положения «драйка» должен выполнить ряд перестроений в базовых пирамидах, в последовательности «драйка» - «колонна на бедрах» «полуколонна на бедрах». Все построения являются базовыми элементами к более сложным техническим построениям.

6-н. Поднимание верхнего скрестным хватом кистей совместно с первым средним. Данное упражнение выполняется в паре с первым средним. Спортсмены образуют скрестный хват кистями - «решётка», становятся в исходное положение для выполнения упражнения. Фиксируются расположение стоп. Задача - на количество выполнить полную амплитуду движения как на «темп», выполняя полное приседание и поднимание верхнего на «решетке».

7-н. Приседания с партнером. Партнер (первый средний) располагается сидя на плечах нижнего, и выполняются приседания с максимальной амплитудой.

8-н. Выпрыгивания с партнером. Партнер (первый средний) располагается сидя на плечах нижнего, и выполняются выпрыгивания из упора присев.

9-н. Удержание партнера в прямых руках. В данном упражнении партнером выступает второй средний. Необходимо удерживать партнера в прямых руках над головой соблюдая технику выполнения упражнения. 
10-н. Перестроение вниз и вверх на возвышение, с удержанием партера в прямых руках. Удерживая своего партнера (второго среднего), стоящего ногами в кистях прямых рук, необходимо выполнить максимальное количество раз поднимание и спускание на возвышение, соблюдая технику исполнения: центр тяжести спортсмена не должен выходить за площадь опоры для сохранения равновесия, спина должна быть чуть-чуть прогнута, а руки должны быть строго вертикальны.

Таблица 13

Дозировка упражнений для первых средних

\begin{tabular}{|c|c|c|c|}
\hline № упражнения & Дозировка & Количество подходов & Примечания \\
\hline 1-H & 30 & 5 & Количество раз \\
\hline $2-\mathrm{H}$ & 290 & 4 & Секунды \\
\hline 3-H & 20 & 5 & Количество раз \\
\hline $4-\mathrm{H}$ & 30 & 4 & Количество раз \\
\hline $5-\mathrm{H}$ & 150 & 5 & Секунды \\
\hline $6-\mathrm{H}$ & 35 & 5 & Количество раз \\
\hline 7-H & 45 & 5 & Количество раз \\
\hline $8-\mathrm{H}$ & 30 & 4 & Количество раз \\
\hline $9-\mathrm{H}$ & 150 & 4 & Количество раз \\
\hline 10-H & 20 & 4 & Количество раз \\
\hline
\end{tabular}

Предложенные упражнения должны выполняться в конце основной части занятия, перед выполнением заданий общей и специальной физической подготовки. Все упражнения могут выполняться с отягощениями - 0,5 кг (для верхних), 1 кг (для средних) и 1,5 кг (для нижних). Отягощения используются в двух комплектах на руки и на ноги занимающихся.

После проведения контроля уровня технической подготовленности высококвалифицированных акробатов, специализирующихся в мужских группах, было необходимо разработать последовательность применения средств совершенствования уровня технической подготовленности.

Из подобранных средств совершенствования технической подготовленности и их дозировки, была составлена последовательность, совершенствования технической подготовленности высококвалифицированных акробатов, специализирующихся в мужских группах, рассчитанная на недельный микроцикл (табл. 14). 


\section{Таблица 14}

\section{Программа совершенствования уровня технической подготовленности}

\section{высококвалифицированных акробатов}

\begin{tabular}{|l|l|l|l|l|}
\hline \multirow{2}{*}{ День недели } & \multicolumn{4}{|c|}{ № упражнения } \\
\cline { 2 - 5 } & Верхний & Второй средний & Первый средний & Нижний \\
\hline Понедельник & 1-в, 3-в, & 1-вс, 3-вс, & 1-пс, 3-пс, & 1-н, 3-н, \\
& 7-в, 9-в & 7-вс, 9-вс & 7-пс, 9-пс & 7-н, 9-н \\
\hline Вторник & 2-в, 5-в, & 2-вс, 5-вс, & 2-пс, 5-пс, & 2-н, 5-н, \\
& 8-в, 10-в & 8-вс, 10-вс & 8-пс, 10-пс & 8-н, 10-н \\
\hline Среда & 1-в, 3-в, 4-в, & 1-вс, 3-вс, 4-вс, & 1-пс, 3-пс, 4-пс, & 1-н, 3-н, 4-н, \\
& 6-в, 8-в, 10-в, 11-в & 6-вс, 8-вс, 10-вс & 6-пс, 8-пс, 10-пс & 6-н, 8-н, 10-н \\
\hline Четверг & 2-в, 5-в, & 2-вс, 5-вс, & 2-пс, 5-пс, & 2-н, 5-н, \\
& 7-в, 9-в & 7-вс, 9-вс & 7-пс, 9-пс & 7-н, 9-н \\
\hline Пятница & 1-в, 3-в, & 1-вс, 3-вс, & 1-пс, 3-пс, & 1-н, 3-н, \\
& 9-в, 11-в & 6-вс, 9-вс & 6-пс, 9-пс & 6-н, 9-н \\
\hline Суббота & 2-в, 4-в, 6-в, & 2-вс, 4-вс, 6-вс, & 2-пс, 4-пс, 6-пс, & 2-н, 4-н, 6-н, \\
& 8-в, 9-в, 10-в & 8-вс, 9-вс, 10-вс & 8-пс, 9-пс, 10-пс & 8-н, 9-н, 10-н \\
\hline Воскресенье & \multicolumn{4}{|c|}{ Выходной } \\
\hline
\end{tabular}

Представленная

последовательность

применения

средств совершенствования технической подготовленности рассчитана на двухпиковый тренировочных микроцикл и может применяться на этапе специальной физической подготовки в годичном макроцикле в процессе многолетней подготовки спортсменов высокой квалификации.

\section{4 Проверка эффективности предложенной последовательности}

\section{применения средств совершенствования технической подготовленности}

Для проверки эффективности предложенной последовательности применения средств совершенствования технической подготовленности высококвалифицированных акробатов, специализирующихся в мужских группах, был проведен педагогический эксперимент.

Основной задачей эксперимента по совершенствованию уровня технической подготовленности высококвалифицированных мужских групп была проверка эффективности предложенной программы, а также проверка эффективности внедрения специальных упражнений в тренировочный процесс высококвалифицированных мужских групп.

В эксперименте участвовали высококвалифицированные акробаты, специализирующиеся в мужских групповых упражнениях в количестве 10-ти составов. 
Эксперимент длился 6 месяцев, испытуемые тренировались по предложенной нами программе. Для фиксации результатов педагогического эксперимента было проведено тестирование уровня технической подготовленности до и после эксперимента.

Результаты исследования представлены в табл. 15.

Таблица 15

Результаты педагогического эксперимента совершенствования технической подготовленности высококвалифицированных акробатов $(\mathbf{n}=10)$

\begin{tabular}{|c|c|c|c|c|c|c|}
\hline \multirow{2}{*}{$\begin{array}{l}\text { № } \\
\Pi / \Pi\end{array}$} & \multirow{2}{*}{ Тесты } & \multicolumn{2}{|c|}{$\mathrm{M} \pm \mathrm{m}$} & \multirow{2}{*}{$\mathrm{T} \%$} & \multirow{2}{*}{$\mathrm{t}$} & \multirow{2}{*}{$\mathrm{P}$} \\
\hline & & До & После & & & \\
\hline 1 & 2 & 3 & 4 & 5 & 6 & 7 \\
\hline \multicolumn{7}{|c|}{ Верхние } \\
\hline 1. & $\begin{array}{l}\text { Выполнение сальто назад в группировке с } \\
\text { места на ограниченной площадке } \\
\text { (количество раз) }\end{array}$ & $9,8 \pm 0,54$ & $11,7 \pm 0,44$ & 16,2 & 2,73 & $<0,05$ \\
\hline 2. & $\begin{array}{l}\text { Удержание стойки на одной руке на } \\
\text { стоялках (c) }\end{array}$ & $195,8 \pm 1,6$ & $201,4 \pm 1,4$ & 2,7 & 2,63 & $<0,05$ \\
\hline 3. & $\begin{array}{l}\text { Удержание упора углом на одной руке на } \\
\text { полу (c) }\end{array}$ & $144,2 \pm 26,19$ & $169,7 \pm 19,98$ & 15,02 & 2,4 & $<0,05$ \\
\hline 4. & $\begin{array}{l}\text { Стойка силой из упора углом на стоялках } \\
\text { (количество раз) }\end{array}$ & $26,3 \pm 4,08$ & $29,7 \pm 4,14$ & 11,44 & 2,32 & $<0,05$ \\
\hline 5. & $\begin{array}{l}\text { Стойка на одной руке силой из упора углом } \\
\text { на голове партнера (количество раз) }\end{array}$ & $2,0 \pm 0,75$ & $3,1 \pm 0,71$ & 55,0 & 1,07 & $>0,05$ \\
\hline \multicolumn{7}{|c|}{ Вторые средние } \\
\hline 1. & $\begin{array}{l}\text { Бросок верхнего двумя руками с } \\
\text { последующей ловлей (темп из рук в руки) } \\
\text { (количество раз) }\end{array}$ & $16,4 \pm 0,9$ & $19,3 \pm 0,34$ & 15,03 & 3,01 & $<0,05$ \\
\hline 2. & Удержание упора углом на стоялках (c) & $217,2 \pm 3,51$ & $228,5 \pm 3,55$ & 4,9 & 2,26 & $<0,05$ \\
\hline 3. & $\begin{array}{l}\text { Приседания с верхним удерживаемым в } \\
\text { прямых руках (количество раз) }\end{array}$ & $12,5 \pm 0,63$ & $14,6 \pm 0,55$ & 14,38 & 2,51 & $<0,05$ \\
\hline 4. & $\begin{array}{l}\text { Удержание верхнего в прямых руках на } \\
\text { ограниченной опоре (c) }\end{array}$ & $118,3 \pm 3,22$ & $129,6 \pm 3,07$ & 8,72 & 2,54 & $<0,05$ \\
\hline 5. & Удержание верхнего на голове (c) & $141,8 \pm 3,51$ & $154,8 \pm 3,36$ & 8,4 & 2,68 & $<0,05$ \\
\hline \multicolumn{7}{|c|}{ Первые средние } \\
\hline 1. & $\begin{array}{l}\text { Бросок «темп» верхнего скрестным хватом } \\
\text { кистей с нижним с последующей ловлей } \\
\text { (количество раз) }\end{array}$ & $18,2 \pm 0,32$ & $19,9 \pm 0,56$ & 8,54 & 2,64 & $<0,05$ \\
\hline 2. & $\begin{array}{l}\text { Удержание партнеров в «драйке» на } \\
\text { ограниченной опоре (c) }\end{array}$ & $170,9 \pm 2,14$ & $180,6 \pm 2,46$ & 5,37 & 2,97 & $<0,05$ \\
\hline 3. & Приседания в «драйке» (количество раз) & $18,3 \pm 0,87$ & $22,0 \pm 0,94$ & 16,81 & 2,89 & $<0,05$ \\
\hline
\end{tabular}




\begin{tabular}{|l|l|l|l|l|l|l|}
\hline 4. & $\begin{array}{l}\text { Приседания с верхним удерживаемым в } \\
\text { прямых руках (количество раз) }\end{array}$ & $21,7 \pm 0,31$ & $23,6 \pm 0,57$ & 8,05 & 2,93 & $<0,05$ \\
\hline 5. & Удержание партнера в прямых руках (с) & $151,2 \pm 1,83$ & $160,4 \pm 2,82$ & 5,74 & 2,74 & $<0,05$ \\
\hline Нижние & & & & & \\
\hline & \multicolumn{5}{|l|}{} \\
\hline 1. & $\begin{array}{l}\text { Бросок верхнего скрестным хватом кистей с } \\
\text { первым средним (решетка) (количество раз) }\end{array}$ & $18,2 \pm 3,32$ & $19,9 \pm 3,56$ & 8,54 & 2,64 & $<0,05$ \\
\hline 2. & Удержание партнеров в «драйке» (с) & $251,7 \pm 11,34$ & $264,2 \pm 8,11$ & 4,73 & 2,92 & $<0,05$ \\
\hline 3. & Приседания в «драйке» (количество раз) & $17,8 \pm 2,1$ & $20,7 \pm 1,65$ & 14,01 & 2,27 & $<0,05$ \\
\hline 4. & $\begin{array}{l}\text { Комплекс перестроений из трех } \\
\text { статистических баз (количество раз) }\end{array}$ & $24,0 \pm 3,27$ & $27,3 \pm 2,68$ & 12,09 & 0,78 & $>0,05$ \\
\hline 5. & Ходьба в «драйке» (с) & $93,6 \pm 5,82$ & $100,9 \pm 5,21$ & 7,24 & 2,55 & $<0,05$ \\
\hline
\end{tabular}

Как видно из табл. 15, по результатам исследования почти по всем показателям модельных характеристик произошел достоверный прирост показателей, что позволяет предполагать об эффективности предложенной последовательности применения средств.

Среди верхних средний темп прироста показателей составил 20,07\% прироста показателей, достоверными приростами оказались 4 из 5 критерием. Среди вторых средних средний темп прироста показателей составил 10,29\% прироста показателей, достоверными оказались все результаты по предложенным критериям. Среди первых средних средний темп прироста показателей составил 8,9\% прироста показателей, достоверные результаты были получены по всем предложенным критериям. И среди нижних средний темп прироста показателей составил 9,25\%, достоверными показателями обладали 4 из 5 предложенных тестов.

Не достоверными оказались два показателя, у верхних - «Стойка на одной руке силой из упора углом на голове партнера» и у нижних - «Комплекс перестроений из трех статистических баз». Это может сигнализировать о том, что в процессе тестирования была допущена ошибка в измерениях, либо данные тесты не являются достоверными для определения уровня технической подготовленности высококвалифицированных акробатов, специализирующихся в мужских группах.

Подводя итог можно отметить, что результаты данного исследования могут способствовать совершенствованию процесса спортивной подготовки в акробатике на всех этапах многолетней подготовки спортсменов. Как следствие планируется более углубленное исследование данной темы и разработка 
соответствующих методик и программ для эффективного контроля технической подготовленности высококвалифицированных акробатов.

\section{Список литературы}

1. Болобан В.Н. Анализ техники акробатических упражнений: методические рекомендации /В.Н. Болобан: - Киев: УГУФВС, 1994. - 32 с.

2. Анцупов Е.А., 50 лет российской акробатики / Анцупов Е.А. Воронеж, 1999. - 90 с.

3. Иссурин В.Б. Подготовка спортсменов XXI века: научные основы и построение тренировки /В.Б. Иссурин; пер. с англ. И. Шаробайко. - Москва: Спорт, 2016. - 464 с.

4. Зациорский В.М. Физические качества спортсмена: основы теории и методики воспитания. Серия «Спорт без границ»/В.М. Зациорский. - М.: Советский спорт, 2009. - 200 с.

5. Аркаев Л.Я., Как готовить чемпионов /Л.Я. Аркаев, Н.Г. Сучилин. Москва: Ф и С, 2004. - 328 с.

6. Жигайлова, Л.В., Береславская, Н.В., Барчо, О.Ф., Тронев, В.В. / Тестирование технической подготовленности акробатов мужских групп высокой квалификации / Педагогика \& Психология. Теория и практика. Волгоград: научное образование. - № 4.2018 год - С. 35-37.

7. Курысь В.Н. Основы познания физического упражнения: Учебное пособие /В.Н. Курысь. - Ставрополь: Изд-во СГУ, 1998. - 130 с.

8. Лысенко В.В. Основы математической обработки измерений в физической культуре: учебное пособие /В.В. Лысенко, Е.В. Мирзоева. Краснодар: КГУФКСТ, 2012. - 210 с. 